médecine/sciences $1990 ; 6: 778-84$

\title{
La structure des récepteurs de la prolactine et de l'hormone de croissance est maintenant connue
}

Le récepteur de la prolactine appartient à une famille de récepteurs à un seul segment transmembranaire où l'on trouve aussi ceux de l'hormone de croissance, de plusieurs interleukines, de l'érythropoïétine et du GMCSF. Ces molécules n'ont pas d'activité intrinsèque de tyrosine kinase et on ne connaît pas leur mécanisme de transduction du signal hormonal. La possession des $\mathrm{ADNc}$ et des gènes correspondants va maintenant permettre de mener des études de relations structurefonction et de déterminer les éléments d'ADN qui confèrent la réponse de gènes variés à ces hormones.

\section{Paul A. Kelly \\ Jean Djiane \\ Jean-Marie Boutin Marc Edery}

\section{ADRESSES}

P.A. Kelly : professeur de médecine et de physiologie. Université McGill, laboratoire d'endocrinologie moléculaire, hôpital Royal Victoria, 687, avenue des Pins ouest, Montréal, Québec H3A 1A1, Canada. J. Djiane : directeur de recherche. Institut national de la recherche agronomique, unité d'endocrinologie moléculaire, bâtiment des biotechnologies, Crj, 78350 Jouy-en-Josas, France. J.M. Boutin : stagiaire de recherche. Université McGill. Boursier du conseil de recherches du Canada. Son adresse actuelle est : Eukaryotic Biology Program, School of medicine, M-013, La Jolla, California 92093, USA. M. Edery : Chargé de recherche. Inserm, unité d'endocrinologie moléculaire, Inra-Crj,

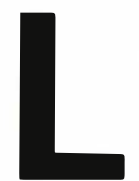

a prolactine (PRL), l'hormone de croissance $(\mathrm{GH})$ et l'hormone lactogène placentaire (PL) forment une même famille d'hormones polypeptidiques [1]. La prolactine et l'hormone de croissance sont sécrétées par l'hypophyse antérieure alors que l'hormone lactogène placentaire est une hormone de la gestation synthétisée par les membranes fœtales du placenta. La PRL et la GH sont présentes chez tous les vertébrés. L'action principale de la $\mathrm{GH}$ est la stimulation de la croissance du squelette et des tissus mous. Les effets peuvent être divisés en deux grandes catégories : ceux associés à la croissance, qui sont indirects puisqu'ils passent par l'intermédiaire de l'IGF ${ }_{1}$ (insulin growth factor 1) et les effets associés au métabolisme des glucides et des lipides, qui semblent être directs et mettent en jeu les récepteurs de la $\mathrm{GH}$ dans les tissus cibles. Pour la prolactine, plus de 85 actions biologiques ont été décrites [2, 3]. Ces actions peuvent être classées en sept catégories : 1) actions associées à l'équilibre de l'eau et des électrolytes ; 2) effets sur la croissance et le développement ; 3) action sur les fonctions de reproduction; 4) effets métaboliques ; 5) effets sur le comportement ; 6) fonction d'immunorégulation et 7) action sur l'ectoderme et la peau.

Certaines de ces fonctions sont caractéristiques de certaines espèces, mais sont moins importantes dans d'autres. Chez les mammifères, l'action la mieux connue de la PRL est celle exercée sur le développement de la glande mammaire et la lactogenèse, c'est-à-dire la production des protéines (caséines, lactalbumine) et des lipides du lait [4]. Ces effets s'exercent en association avec d'autres hormones, comme l'œstradiol, la progestérone, les glucocorticoïdes, la GH, l'hormone lactogène placentaire, l'insuline, les hormones thyroïdiennes et les facteurs de croissance.

Les mécanismes d'action cellulaire de la prolactine et de l'hormone de croissance restent peu connus. En particulier, les étapes postérieures à l'interaction de ces hormones avec leurs récepteurs spécifiques, qui sont responsables du transfert de la stimulation hormonale, restent inconnues 
et aucun "second messager " pour ces hormones n'a encore été identifié. Il est clair que la PRL est une hormone clé impliquée dans le développement et le maintien de certaines tumeurs expérimentales de la glande mammaire chez les rongeurs. Le rôle de la PRL dans le cancer du sein est en revanche beaucoup plus controversé. Toutefois, les récepteurs de la prolactine sont présents dans la majorité des biopsies tumorales et dans des lignées cellulaires dérivées de ces tumeurs [5].

\section{Distribution des récepteurs}

Les récepteurs de la prolactine ont une distribution beaucoup plus large que celle des récepteurs de l'hormone de croissance (Tableau I). Cependant, l'hormone de croissance peut agir indirectement sur un grand nombre de tissus via la production hépatique d'IGF 1 [6].

\section{Régulation des récepteurs}

La régulation hormonale des récepteurs de la prolactine et de l'hormone de croissance est complexe. Plusieurs hormones stéroïdes, thyroïdiennes et polypeptidiques, incluant la prolactine et l'hormone de croissance ellesmêmes, contrôlent le niveau des récepteurs. Par exemple chez le rat, la testostérone augmente le nombre de récepteurs de la prolactine dans la prostate, alors que cette même hormone diminue ces récepteurs dans le foie, le rein et la surrénale. En revanche, les œstrogènes augmentent le nombre de récepteurs dans le foie. Il est probable que les hormones stéroïdes agissent indirectement, au moins partiellement, via la sécrétion hypophysaire de la prolactine et de l'hormone de croissance. Ces deux hormones ont un rôle direct sur la régulation positive de leurs propres récepteurs, et la $\mathrm{GH}$ est capable aussi d'augmenter le niveau des récepteurs de la prolactine (pour une revue, [6]). La prolactine et l'hormone de croissance exercent aussi un contrôle négatif sur leurs propres récepteurs. Cette régulation négative (downregulation) s'exerce soit à des concentrations, soit à des durées d'exposition à l'hormone, plus élevées que pour la régulation positive [6].

\section{Structure des récepteurs}

Le développement des anticorps poly- clonaux et monoclonaux dirigés contre les récepteurs de la prolactine et de l'hormone de croissance a joué un rôle déterminant dans la caractérisation et, surtout pour la prolactine, dans la purification des récepteurs.

\section{Récepteurs de la prolactine}

Plusieurs anticorps monoclonaux différents dirigés, soit contre le récepteur de la glande mammaire de lapine $[7,8]$, soit contre le récepteur du foie de rat $[9,10]$, ont été développés. L'un de ces anticorps, dirigé contre le récepteur de la prolactine de la glande mammaire de lapine (A917), est doué de propriétés mimétiques de la prolactine sur la glande mammaire, alors que d'autres anticorps, dirigés contre le site de liaison, sont capables de bloquer l'action biologique de la prolactine [8]. Ces anticorps ont facilité la caractérisation biochimique du récepteur de la prolactine dans différents tissus chez le rat et le lapin.

Chez le rat, l'un des tissus présentant la concentration en récepteur de la prolactine la plus élevée est le foie. Bien que la fonction exacte de la prolactine dans ce tissu ne soit pas clairement établie (la stimulation de l'ornithine décarboxylase [11] et de la synlactine [12] a été décrite), le foie reste un bon modèle pour étudier la biochimie du récepteur. L'un des anticorps monoclonaux (E21) se lie au récepteur du foie de rat avec une affinité élevée, simule la liaison de la prolactine à son récepteur et immunoprécipite spécifiquement une protéine d'un poids moléculaire apparent d'environ 42000 [9]. Un poids moléculaire identique est trouvé par western blot $[9,10]$. Le poids moléculaire du récepteur a été déterminé par une approche non immunologique. Lorsqu'une préparation membranaire ou partiellement purifiée en récepteur est marquée par pontage covalent avec la ${ }^{125}$ I-prolactine (crosslinking), l'analyse sur gel de polyacrylamide révèle une bande d'environ 62000 correspondant au complexe hormonerécepteur (figure 1). Compte tenu du poids moléculaire de la prolactine (22 000), cette analyse révèle à nouveau un poids moléculaire apparent d'environ 40000 du récepteur.

\section{Clonage de l'ADNc du récepteur de la prolactine}

Le clonage a été réalisé par une approche classique. La purification complète du récepteur du foie de rat par chromatographie d'immunoaffi-

\begin{tabular}{|c|c|}
\hline \multicolumn{2}{|c|}{$\begin{array}{l}\text { Tableau I } \\
\text { UTION DES RÉCEPTEURS DE LA PROLACTINE } \\
\text { ET DE L'HORMONE DE CROISSANCE }\end{array}$} \\
\hline Prolactine & Hormone de croissance \\
\hline $\begin{array}{l}\text { Glande mammaire normale } \\
\text { Tumeur mammaire } \\
\text { Foie } \\
\text { Pancréas } \\
\text { Rein } \\
\text { Surrénale } \\
\text { Placenta } \\
\text { Ovaire: cellules de granulosa et } \\
\quad \text { corps jaune } \\
\text { Testicule: cellules de Leydig } \\
\text { Epididyme } \\
\text { Vésicule séminale } \\
\text { Prostate } \\
\text { Lymphocytes } \\
\text { Thymocytes } \\
\text { Plexus choroïde } \\
\text { Hypothalamus }\end{array}$ & $\begin{array}{l}\text { Foie } \\
\text { Tissu adipeux } \\
\text { Lymphocytes } \\
\text { Thymocytes } \\
\text { Ovaire } \\
\text { Corps jaune }\end{array}$ \\
\hline
\end{tabular}




\section{RÉFÉRENCES}

1. Niall HD, Hogan ML, Sayer R, Rosenpituitary and placental lactogenic and growth hormones. Evolution from a primordial peptide by gene duplication. Proc Natl Acad Sci USA 1971 ; 68 : 866-9.

2. Nicoll CS, Bern HA. On the actions of common denominator? In : Wolstenholme GEW, Knight J, eds. Lactogenic Hormones. London: Churchill-Livingstone, 1972: 299-317.

3. Meites J. Biological functions of prolactin. In : Hoshino K, ed. Prolactin Gene Family and its Receptors. Amsterdam : Elsevier Science Publishers BV, 1988 : 123-30.

4. Shiu RPC, Friesen HG. Mechanism of action of prolactin in the control of mammary gland function. Ann Rev Physiol 1980 ; 42 : 83-96.

5. Welsch CW, Nagasawa H. Prolactin and murine mammary tumorigenesis : a review. Cancer Res 1977 ; 37 : 951-63.

6. Hughes JP, Elsholtz HP, Friesen HG. Growth hormone and prolactin receptors. In : Posner BI, ed. Polypeptide Hormone Receptors. New York: Marcel Dekker, 1985: 157-99.

7. Katoh M, Djiane J, Kelly PA. Monoclonal antibodies against rabbit mammary prolactin receptors : specific antibodies to the hormone binding domain. $J$ Biol Chem 1985 : 11422-9.

8. Djiane J, Dusanter-Fourt I, Katoh M, Kelly PA. Biological activities of binding site specific monoclonal antibodies to the prolactin receptor of rabbit mammary gland. J Biol Chem 1985 ; 260 : 11430-5.

9. Katoh M, Raguet S, Zachwieja J, Djiane J, Kelly PA. Hepatic prolactin receptors in the rat : characterization using monoclonal antireceptor antibody. Endocrinology $1987 ; 120$ : 739-49. blum IY, Greenwood FC. Sequences of prolactin among the vertebrates : is there a

nité suivie par électrophorèse préparative, a rendu possible la détermination de la séquence primaire en acides aminés des fragments du récepteur. Il fallait atteindre un facteur de purification de l'ordre de 100000 fois pour obtenir une préparation homogène. Les fragments peptidiques obtenus par digestion partielle du récepteur par la trypsine ont été purifiés par chromatographie en phase liquide à haute performance (HPLC), et la séquence en acides aminés a été déterminée par analyse en phase gazeuse $[13,14]$. Une sonde oligonucléotidique, préparée à partir des séquences en acides aminés des fragments, a été utilisée pour cribler une banque d'ADN complémentaire construite à partir des ARN messagers du foie de rat. Un premier $\mathrm{ADNc}$ de petite taille a été isolé, qui a ensuite été utilisé comme sonde pour trouver l'ADNc complet du récepteur de la prolactine.

La structure de cet ADNc a permis de déduire l'enchaînement des acides aminés du récepteur. La protéine mature, dans le foie de rat, est composée de 291 aa, avec une zone extracellulaire de 210 aa, une région transmembranaire unique de 24 aa, et une région cytoplasmique de 57 aa [13] (figure 2). L'introduction par transfection de cet $\mathrm{ADNc}$ dans les cellules hôtes permet d'exprimer le récepteur dans les cellules qui en sont normalement dépourvues et d'établir sans ambiguïté l'identité du clone sélectionné. Le récepteur de la prolactine a donc été exprimé dans les cellules de mammiferes, les cellules

Figure 1. Caractérisation du récepteur de la prolactine de rat. A. Liaison covalente de $125 /$-prolactine à son récepteur hépatique, en absence (puits 1) ou en présence (puits 2) d'un excès de prolactine non marquée. Les marqueurs de poids moléculaire sont indiqués à gauche. Le poids moléculaire du complexe hormone-récepteur est de 61 000. B. Caractérisation par immunoblot du récepteur de la prolactine. Le poids moléculaire du récepteur est d'environ 41000 d'ovaire du hamster chinois (CHO), par transfection avec un plasmide contenant l'ADNc du récepteur lié à différents éléments du génome du virus SV40 (pour faciliter l'efficacité de l'expression). L'expression du récepteur dans les cellules hôtes a été démontrée par mesure de la liaison spécifique de la prolactine. Les cellules transfectées expriment des récepteurs qui ont une spécificité et une affinité pour la prolactine identiques à celles déjà observées pour le récepteur de la prolactine du foie de rat ou de la glande mammaire de lapine.

L'ensemble des résultats obtenus (séquence en acides aminés, structure, poids moléculaire, liaison spécifique de la prolactine, affinité du récepteur pour les différentes hormones étudiées) démontre donc que l'ADNc isolé code bien pour le récepteur de la prolactine du foie de rat.

\section{Récepteur de l'hormone de croissance}

Quelques mois avant la publication de notre travail sur le récepteur de la prolactine, des chercheurs de la firme Genentech à San Francisco ont publié la structure du récepteur de l'hormone de croissance, déterminée selon les mêmes techniques, c'est-à-dire après purification, séquençage et clonage de l'ADNc [15]. Ces auteurs ont signalé que la structure établie ne présentait d'homologie avec aucune protéine connue. En fait, après notre travail, nous avons constaté que la structure que nous avions déterminée pour le récepteur de la prolactine, présentait d'importantes homologies avec celles du récepteur de l'hormone de croissance (figure $3, p$. 782). A première vue, la structure des deux récepteurs semble être très différente, puisque le récepteur de l'hormone de croissance est beaucoup plus long (620 aa). Cependant, si on compare seulement les premiers 291 aa, $30 \%$ d'entre eux sont identiques entre les deux récepteurs. De plus, l'homologie se concentre dans certains domaines où l'on trouve jusqu'à $70 \%$ d'acides aminés identiques. Les récepteurs de la prolactine et de l'hormone de croissance forment donc une nouvelle famille de récepteurs qui possède une seule région transmembranaire. 


\section{Une seconde forme de récepteurs de la prolactine}

En utilisant l'ADNc du récepteur du foie de rat comme sonde, une banque d'ADN complémentaires, construite à partir de glande mammaire de lapine, a été criblée. Nous avons isolé deux $\mathrm{ADNc}$ qui, associés, délimitent un cadre de lecture codant pour le récepteur de la prolactine. Dans ce tissu, le récepteur mature a une longueur de 592 acides aminés avec les domaines extracellulaire et transmembranaire très voisins de ceux du récepteur du foie de rat (figure 3). La différence est localisée dans la partie cytoplasmique qui est composée de 358 acides aminés [16], c'est-à-dire beaucoup plus longue que dans le cas du récepteur du foie de rat (57 acides aminés).

Encore plus récemment, la structure du récepteur de la prolactine chez l'homme a été déterminée en criblant des banques d'ADNc d'une lignée cellulaire d'hépatome (Hep G2) et d'une lignée de cellules de cancer du sein (T-47D). Le récepteur de la prolactine chez l'homme appartient à cette deuxième catégorie de récepteurs (forme longue) avec 598 acides aminés pour la forme mature (figure 3) [17]. Il est probable que les deux formes de récepteurs de la PRL sont responsables de différentes actions biologiques. Dans la partie cytoplasmique du récepteur de la forme longue, chez l'homme ou le lapin, trois régions supplémentaires d'acides aminés identiques (50-100\%) à ceux du récepteur de l'hormone de croissance ont été mises en évidence. Il est tout à fait possible que ces régions de similarité soient impliquées dans le transfert du signal hormonal à l'intérieur de la cellule.

\section{Identification d'une plus grande famille de récepteurs}

La famille qui comprend les récepteurs de la prolactine et de l'hormone de croissance s'est récemment élargie. En effet, il a été démontré que les récepteurs de certains facteurs de croissance comme l'interleukine-2 (p75 ou chaîne $\beta$ ), l'interleukine-4, l'interleukine-6, l'érythropoïétine et le $\mathrm{m} / \mathrm{s} n^{\circ} 8$, vol. 6, octobre 90

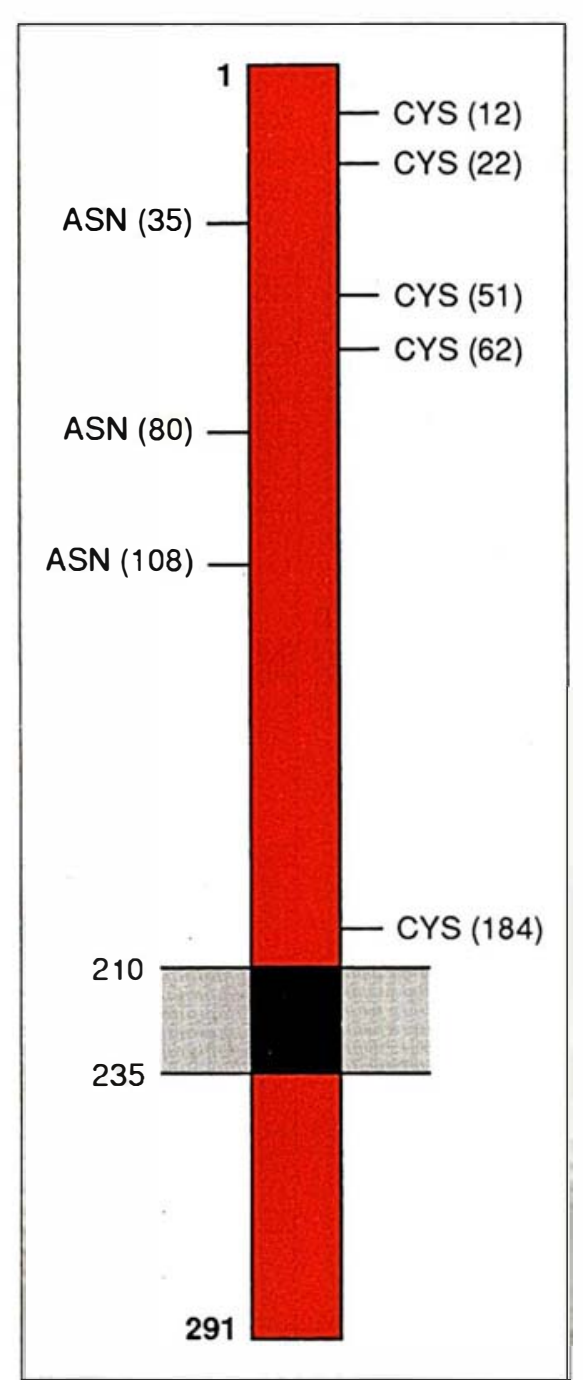

Figure 2. Schéma de la structure du récepteur de la prolactine. La région transmembranaire est représentée en noir. Le premier et le dernier acide aminé de la protéine mature sont numérotés ainsi que les acides aminés délimitant la région transmembranaire. Les cystéines et les sites potentiels de glycosylation dans la région extracellulaire sont indiqués.

GM-CSF (granolocyte-macrophage colony stimulating factor) présentent une homologie avec les récepteurs de la prolactine et l'hormone de croissance [18-20]. Comme le montre la figure 4, p. 783, l'homologie entre ces récepteurs est localisée dans les domaines extracellulaires où se lient leurs ligands spécifiques. Il sera intéressant d'analyser, dans l'avenir, s'il existe des interactions entre ces facteurs de croissance, ou s'il peut être mis en évidence des étapes communes dans leurs mécanismes d'action.

Tests fonctionnels des récepteurs Dans nos laboratoires, nous établissons actuellement des tests fonctionnels des récepteurs de la prolactine et de l'hormone de croissance. Nous utilisons deux approches : premièrement, la transfection dans les cellules reconnues comme cibles (cellules de glande mammaire normale ou tumorale pour la prolactine et cellules hépatiques ou préadipocytaires pour l'hormone de croissance). Les réponses seront mesurées par la quantification des protéines du lait, comme les caséines pour la prolactine et l'IGF-I pour l'hormone de croissance. Nous devrions obtenir une augmentation de la sensibilité à l'hormone en provoquant une expression accrue du récepteur.

Deuxièmement, nous réalisons dans les cellules CHO la cotransfection de l'ADN complémentaire du récepteur et d'un gène cible de la prolactine $(\beta$ lactoglobuline, $\beta$-caséine, parathyroid related peptide (PRP)) ou de l'hormone de croissance (IGF-I), qui est couplé à un gène " traceur " comme celui codant pour la chloramphénicol acétyltransférase (CAT). Par cette approche, nous espérons détecter une stimulation du niveau de la transcription des gènes sensibles aux hormones.

Le développement de ces tests fonctionnels devrait nous permettre d'identifier, par mutagenèse dirigée de l'ADNc des récepteurs des deux hormones, la ou les région(s) impliquée(s) dans le mécanisme d'action de ces hormones.

Régulation du niveau d'ARN messagers des récepteurs

Les niveaux de l'ARNm du récepteur de la prolactine du foie de rat ont été étudiés au cours de l'ontogenèse et après stimulation par l'œstradiol. L'ARNm est indétectable par northern blot chez les animaux hypophysectomisés, alors que ce messager est facilement détectable chez la rate intacte [13]. L'ARNm du récepteur est également absent dans le foie de fœetus ou de nouveau-né, augmente légèrement à l'âge de 21 jours, clairement à 40 jours après la puberté et se stabilise jusqu'à l'âge 


\section{RÉFÉRENCES}

10. Okamura $\mathrm{H}$, Zachwieja J, Raguet $\mathrm{S}$, Kelly PA. Characterization and application of monoclonal antibodies to the prolactin receptor. Endocrinology 1989; 124 : 2499-508.

11. Richards JF. Ornithine decarboxylase activity in tissues of prolactin-treated rats. Biochem Biophys Res Commun 1975; 63 : 292-99.

12. Mick CCW, Nicoll CS. Prolactin directly stimulates the liver in vivo to secrete a factor (synlactin) which acts synergistically with the hormone. Endocrinology 1985; 116 : 2049-53.

13. Boutin JM, Jolicœur C, Okamura H, et al. Cloning and expression of the rat prolactin receptor, a member of the growth hormone/prolactin receptor gene family. Cell $1988 ; 53: 69-77$

14. Okamura H, Raguet S, Bell A, Gagnon J, Kelly PA. Purification and protein sequence analysis of the rat liver prolactin receptor. J Biol Chem 1989; 264 : 5904-11.

15. Leung DW, Spencer SA, Cachianes G, et al. Growth hormone receptor and serum binding protein : purification, cloning and expression. Nature 1987 ; $330: 537-43$.

16. Edery M, Jolicœur C, Levi-Meyrueis $C$, et al. Identification and sequence analysis of a second form of prolactin receptor by molecular cloning of complementary DNA from rabbit mammary gland. Proc Natl Acad Sci USA 1989 ; 86 : 2112-6.

17. Boutin JM, Edery M, Shirota M, et al. Identification of a cDNA encoding a long form of PRL receptor in human hepatoma and breast cancer cells. Mol Endocrinol 1989 ; 1455-61.

18. Bazan JF. A novel family of growth factor receptors : a common binding domain in the growth hormone, prolactin, erythropoietin and IL-6 receptors, and the p75 IL-2 receptor $\beta$-chain. Biochem Biophys Res Commun 1989 ; 164 : 788-95.

19. Moslely B, Beckmann MP, March CJ, et al. The murine interleukin-4 receptor : molecular cloning and characterization of secreted and membrane bound forms. Cell 1989 ; 59 : 335-48.

20. Gearing DP, King JA, Gough NM, Nicola NA. Expression cloning of a receptor for granulocyte-macrophage colonystimulating factor. $E M B O J 1989 ; 8$ :

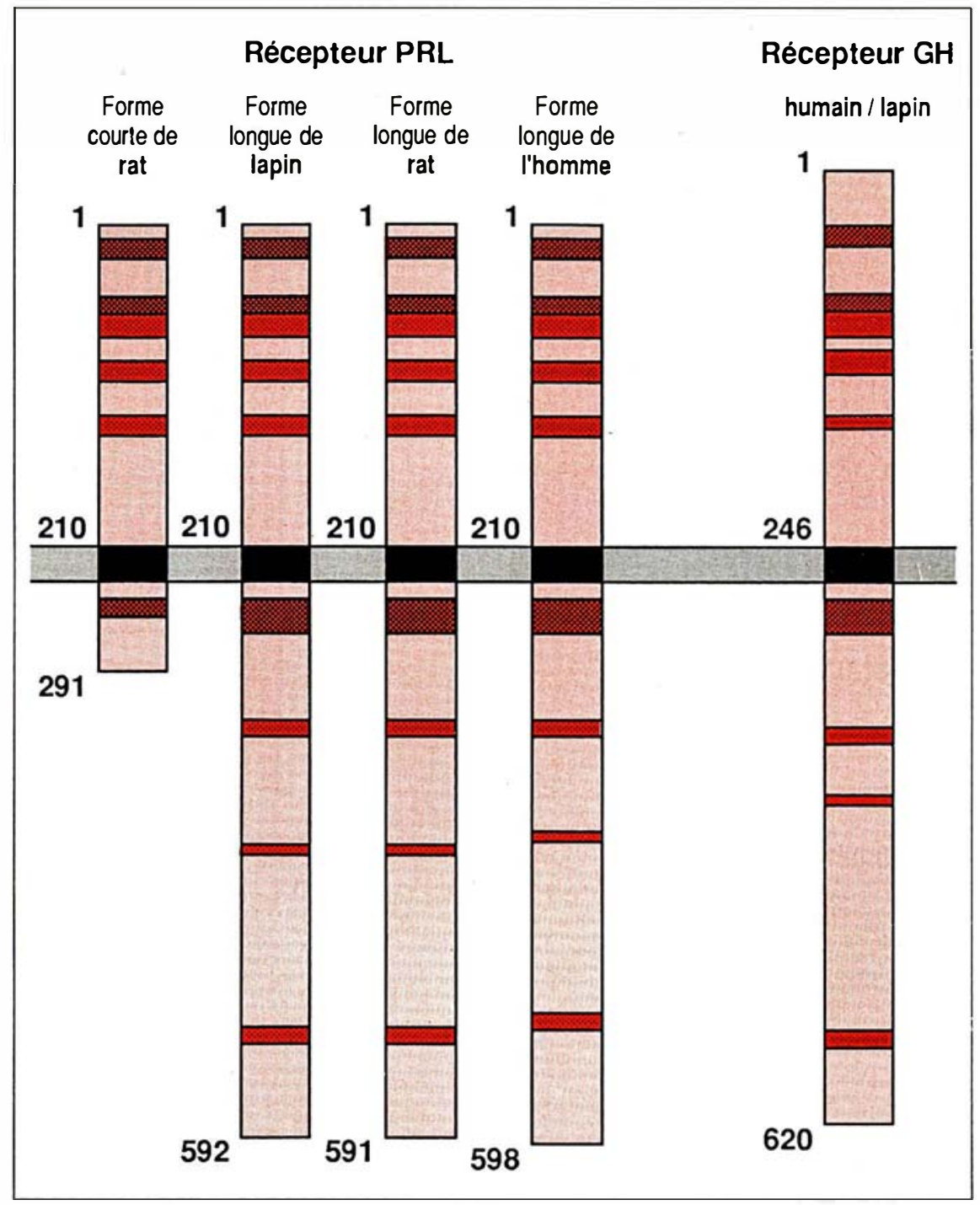

Figure 3. Structure comparée des récepteurs de la prolactine de forme courte de rat, de forme longue de lapin, de rat et d'homme avec les récepteurs de l'hormone de croissance de foie de lapin et d'homme, clonés par le groupe de Genentech [15]. Les chiffres représentent le premier acide aminé de la protéine mature, le dernier acide aminé de la région extracellulaire et le dernier acide aminé du récepteur. Les régions de haute homologie sont indiquées en rouge et d'homologie modérée, en rose foncé.

adulte (70 jours). Les niveaux des récepteurs de la prolactine, mesurés par analyses de Scatchard dans les mêmes échantillons de foie, montrent une évolution presque identique à celle des ARNm jusqu'à 40 jours, ensuite seul le nombre de récepteurs continue à augmenter [21].

Après une injection unique de valérate d'œstradiol $(1 \mathrm{mg})$, on observe une augmentation parallèle de
l'ARNm du récepteur de la prolactine et du nombre de récepteurs pendant les trois premiers jours de traitement ; ensuite, de nouveau, seul le nombre de récepteurs augmente alors que le niveau de l'ARNm se stabilise. Ces résultats suggèrent une double régulation des récepteurs de la prolactine, au niveau de la transcription du gène et aussi au niveau posttranscriptionnel, soit sur la stabilisa- 
tion, soit sur la traduction du message [21]. En ce qui concerne le récepteur de l'hormone de croissance, peu d'études ont été réalisées ; il semble qu'au cours de la gestation, le niveau de l'ARN messager augmente d'environ deux fois [22, 23].

La protéine sérique de liaison de la GH

L'équipe de William Wood (Genentech, Californie) a fortement suggéré que la protéine sérique de liaison de l'hormone de croissance chez le lapin et chez l'homme est en fait constituée d'un fragment du récepteur membranaire [15]. Dans la mesure où il n'a été identifié qu'une seule forme d'ARN messager du récepteur de l'hormone de croissance dans le foie du lapin ou de l'homme, les auteurs ont avancé l'hypothèse que la protéine de liaison circulante est produite par protéolyse du récepteur. Plus récemment, chez la souris [24] et chez le rat [25], un ARN messager spécifique de la protéine de liaison a été identifié. Chez le rat, un ADN complémentaire codant pour une forme sécrétée du récepteur a été isolée [25]. Ces résultats suggèrent qu'un épissage alternatif du gène du récepteur pourrait être responsable de la production de cette protéine de liaison circulante.

Structure des gènes des récepteurs Le récepteur de la prolactine chez le rat est codé par un seul gène, d'une longueur supérieure à $65 \mathrm{~kb}$, constitué d'au moins 11 exons [Banville et al., manuscrit en préparation]. La structure du gène du récepteur de l'hormone de croissance est tout à fait similaire. Il est constitué de 10 exons ( $>87 \mathrm{~kb}$ ) qui sont homologues aux 10 premiers exons du récepteur de la prolactine [26]. Par épissage alternatif au niveau du $11^{\mathrm{e}}$ exon, deux formes du récepteur sont produites (figure 3) chez le rat.

Localisation chromosomique des gènes des récepteurs

Les gènes des récepteurs de la prolactine et de l'hormone de croissance sont situés sur le bras court du chromosome 5 chez l'homme. Plus spécifiquement, par hybridation in situ, les gènes ont été localisés en 5p12-p13.1 [27] ou en 5p13-p14 [28] pour le récepteur de l'hormone de $m / s n^{\circ} 8$, vol. 6, octobre 90

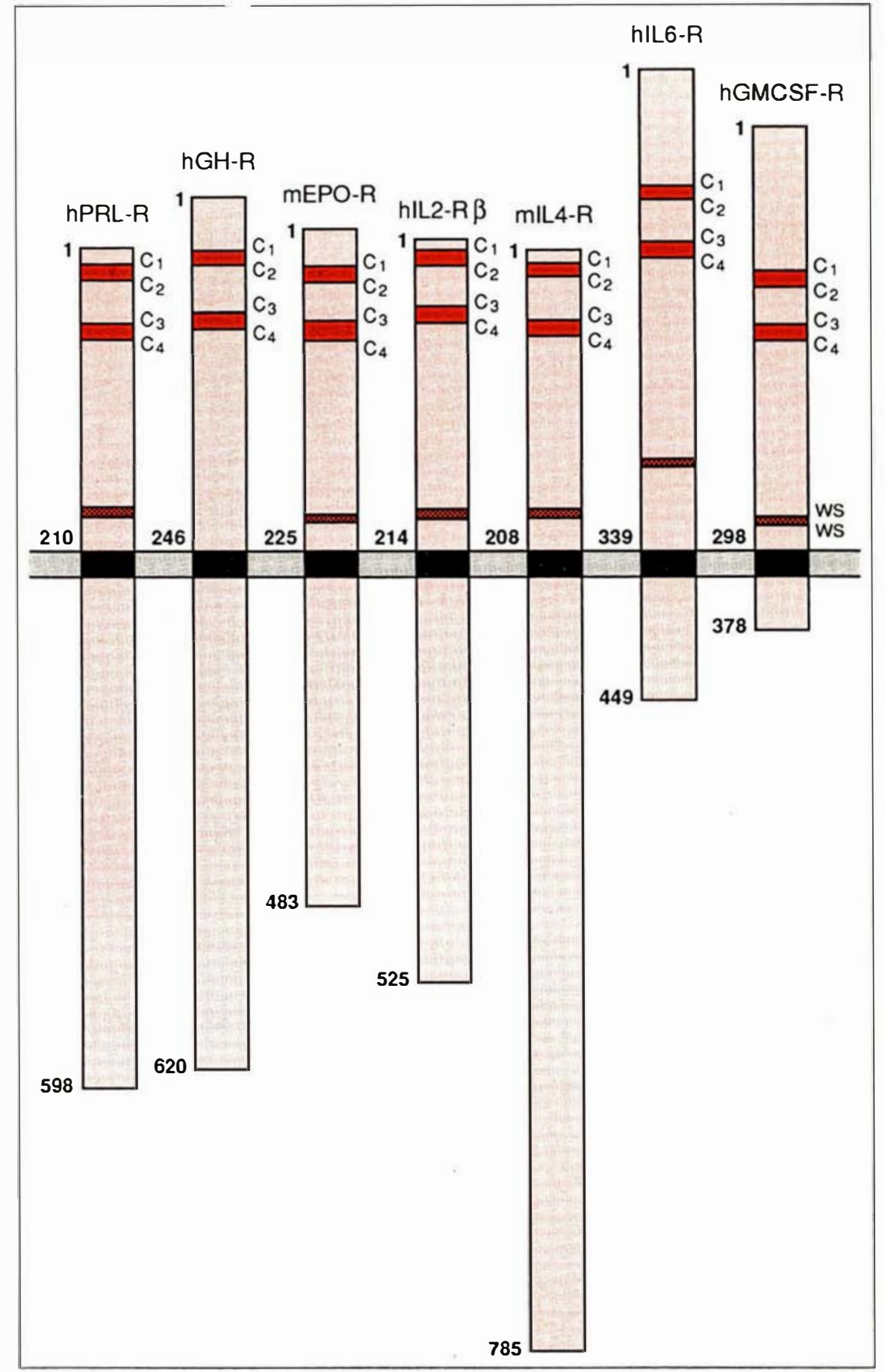

Figure 4. Structure comparée des récepteurs de la prolactine et de l'hormone de croissance avec les récepteurs des différents facteurs de croissance. $h$ : humain ; $m$ : murin ; PRL : prolactine ; GH : hormone de croissance ; IL : interleukine; GM-CSF : colony stimulating factor spécifique des lignées granulomonocytaires ; $C_{1}, C_{2}, C_{3}$ et $C_{4}$ : cystéines conservées; ws et ws : acides aminés tryptophane-sérine-x-tryptophane-sérine (wsxws) conservés. 


\section{RÉFÉRENCES}

21. Jolicœur C, Boutin JM, Okamura $\mathrm{H}$ Raguet S, Djiane J, Kelly PA. Multiple regulation of prolactin receptor gene expression in rat liver. Mol Endocrinol 1989 ; 3 : 895-900.

22. Tiong TS, Freed KA, Herington AC. Identification and tissue distribution of messenger RNA for the growth hormone receptor in the rabbit. Biochem Biophys Res Commun 1989 ; 158 : 141-8.

23. Mathews LS, Enberg B, Norstedt G. Regulation of rat growth hormone receptor gene expression. J Biol Chem 1989; 264 : 9905-10

24. Smith WC, Linzer DIH, Talamantes F. Detection of two growth hormone receptor mRNAs and primary translation products in the mouse. Proc Natl Acad Sci USA $1988 ; 85$ : 9576-9.

25. Brumbach WR, Horner DL, Logan JS. The growth hormone binding protein in rat serum is an alternatively spliced form of the rat growth hormone receptor. Genes Dev 1989 ; 3 : 1199-205.

26. Godowski PJ, Leung DW, Meacham LR, et al. Characterization of the human growth hormone receptor gene and demonstration of a partial gene deletion in two patients with Laron-type dwarfism. Proc Natl Acad Sci USA 1989 ; 86 : 8083-7.

27. Barton DE, Foellmer BE, Wood WI, Francke U. Chromosome mapping of the growth hormone receptor in man and mouse. Cytogenet Cell Genet 1989; 50 : 137-41.

28. Arden KC, Boutin JM, Djiane J, Kelly PA, Cavenee WK. The receptors for prolactin and growth hormone colocalize to the same region of human chromosome 5. Cytogenet Cell Genet 1990 ; 53 : 161-5.

29. Laron Z, Pertzelan A, Mannheimer S. Genetic pituitary dwarfism with high serum concentration of growth hormone : a new inborn error of metabolism? Isr J Med Sci $1966 ; 2$ : 152-5.

30. Laron Z, Pertzelan A, Karp M Kowadlo-Silbergeld A, Daughaday WH. Administration of growth hormone to patients with familial dwarfism with high plasma immunoreactive growth hormone measurement of sulfation factor, metabolic and linear growth response. J Clin Endocrinol Metab 1971; 33 : 332-42.

31. Amselem S, Duquesnoy BS, Attree O, et al. Laron dwarfism and mutations in the human growth hormone receptor gene. New croissance et en 5p13-p14 [28] pour le récepteur de la prolactine. Il est intéressant de noter cette colocalisation chromosomique des gènes des deux récepteurs de la même famille.

\section{Maladies génétiques}

Le nanisme du type Laron est une maladie génétique caractérisée par une résistance à l'hormone de croissance $[29,30]$. Les patients atteints de cette maladie ont un nanisme classique avec un niveau circulant d'IGF, bas malgré la présence d'un niveau élevé de l'hormone de croissance qui est biologiquement active. Récemment, deux groupes ont montré indépendamment que cette maladie peut être due à des mutations ponctuelles dans le gène du récepteur de l'hormone de croissance [26, 31]. Dans un cas, il s'agit d'une mutation ponctuelle qui provoque une seule modification dans la structure nucléotidique et se traduit par le remplacement d'un acide aminé apolaire, la phénylalanine en position 96 , en un acide aminé polaire, la sérine, dans la partie extracellulaire du récepteur. Cette région est hautement conservée entre les récepteurs de l'hormone de croissance et de la prolactine [31]. Dans l'autre exemple de l'analyse génétique de cette maladie, une délétion d'une grande partie du domaine extracellulaire a été détectée [26].

\section{Conclusions}

L'obtention des ADN complémentaires codant pour les récepteurs de la prolactine et de l'hormone de croissance représente une étape importante dans l'étude de la structure et des fonctions de ces récepteurs. A l'aide des anticorps polyclonaux et monoclonaux qui pourront être obtenus à partir de peptides synthétiques pour ces deux récepteurs et en utilisant des sondes nucléotidiques pour quantifier les ARN messagers, nous pourrons mieux comprendre la distribution et la régulation de ces récepteurs. Par ailleurs, les études de mutagenèse dirigée des ADN complémentaires suivies de la transfection dans des systèmes fonctionnels devraient permettre d'identifier les domaines de ces deux récepteurs impliqués dans leur mécanisme d'action

\section{Summary}

The structure of prolactin and growth hormone receptors is now known

The cDNAs of the receptors for the anterior pituitary hormones, prolactin and growth hormone, have been cloned and their primary structures have been deduced. They are single membranespanning receptors that appear to have originated from a common ancestor. This receptor family has recently expanded to include certain growth factor receptors. The mechanism of signal transduction of prolactin and growth hormone is not known. Laron dwarfism can, at least partially, be explained as a genetic defect resulting in a modified receptor molecule incapable of binding the hormone.

\section{TIRÉS A PART}

P.A. Kelly

\section{ERRATUM}

$\mathrm{m} / \mathrm{s}, n^{\circ} 7$, vol. 6, septembre 1990. Il fallait lire page $645: M . Y$. Fiszman : directeur de recherche à l'Inserm. Il avait été omis de préciser que $D$. Libri (page 645) est boursier de l'Association Française des Myopathes. 